\title{
RESEARCH
}

Open Access

\section{Psychosocial and behavioural characteristics in women with pregnancy- related lumbopelvic pain 12 years postpartum}

\author{
Cecilia Bergström ${ }^{1 *}$ D, Margareta Persson ${ }^{1,2}$ and Ingrid Mogren ${ }^{1}$
}

\begin{abstract}
Background: There is insufficient evidence regarding psychosocial factors and its long-term association with persistent pregnancy-related lumbopelvic pain. The overall aim of this study was to investigate women with persistent pregnancy-related lumbopelvic pain 12 years postpartum based on psychosocial and behavioural characteristics using the Swedish version of the Multidimensional Pain Inventory (MPI-S) classification system.

Material and methods: This is a cross-sectional study based on a previous cohort. Data collection took place through a questionnaire. A total of 295 women from the initial cohort $(n=639)$ responded to the questionnaire giving a response rate of $47.3 \%$. To determine the relative risk (RR) of reporting pain 12 years postpartum, a robust modified Poisson regression was used. This is the first study using the MPI-S as a predictive variable on women with persistent pregnancy-related lumbopelvic pain.

Results: The MPI-S classification procedure was carried out on a total of $n=226$ women, where 53 women were classified as interpersonally distressed (ID), 82 as dysfunctional (DYS), and 91 as adaptive copers (AC). Women in the ID and DYS subgroups had a relative risk (RR) of reporting persistent pregnancy-related lumbopelvic pain 12 years postpartum that was more than twice as high compared to the AC subgroup ( $95 \%$ confidence interval $(\mathrm{Cl})$ in parenthesis): RR 2.57 (Cl 1.76 - 3.75), $p<0.0001$ and RR 2.23 (Cl 1.53 - 3.25), $p<0.0001$ respectively. Women in the DYS subgroup had more than 5 times increased risk of reporting sick leave the past 12 months compared to the AC subgroup (RR 5.44; Cl $1.70-17.38, p=0.004$ ).

Conclusions: The present study demonstrates that it is possible to classify women with persistent pregnancyrelated lumbopelvic pain 12 years postpartum into relevant clinical subgroups based on psychosocial and behavioural characteristics using the MPI-S questionnaire.
\end{abstract}

Keywords: Pregnancy-related lumbopelvic pain, Postpartum, Psychosocial characteristics, MPI, Cross-sectional questionnaire study

\footnotetext{
* Correspondence: cecilia.bergstrom@umu.se

'Department of Clinical Sciences, Obstetrics and Gynecology, Umeå

University, 90187 Umeå, Sweden

Full list of author information is available at the end of the article
}

(c) The Author(s). 2019 Open Access This article is distributed under the terms of the Creative Commons Attribution 4.0 International License (http://creativecommons.org/licenses/by/4.0/), which permits unrestricted use, distribution, and reproduction in any medium, provided you give appropriate credit to the original author(s) and the source, provide a link to the Creative Commons license, and indicate if changes were made. The Creative Commons Public Domain Dedication waiver (http://creativecommons.org/publicdomain/zero/1.0/) applies to the data made available in this article, unless otherwise stated. 


\section{Introduction}

Pregnancy-related lumbopelvic pain is not limited to pregnancy. Though most women recover within 6 months postpartum [1, 2], we as well as other researchers have demonstrated in several studies that symptoms can persist from a couple of years up to 12 years postpartum [3-8]. It has been shown that individuals with low back pain (LBP) who transition into a more chronic state take up the majority of the allocated resources [9]. The majority of the societal costs associated with chronicity are indirect cost such as disability, production loss, sickness absence and disability pension [10].

Psychosocial factors have long been associated with chronic pain and the bio-psycho-social model has become the leading theory of the development and management of chronic pain [11]. Psychosocial factors have also been demonstrated to play a crucial role in the transition from acute and sub-acute pain to chronicity [12-14]. In patients with musculoskeletal pain, psychosocial factors appear to exacerbate the clinical component of pain $[15,16]$ and have shown to influence future disability, pain, self-reported improvement after treatment in patients with LBP [17-21]. Even though pregnancy itself negatively influences health related quality of life lumbopelvic pain increases this influence [22]. Pregnancy-related lumbopelvic pain has also been shown to have great negative emotional and psychological impact on women [23]. Daily stress has been demonstrated to be a risk factor for pregnancy-related lumbopelvic pain [24] and women with postpartum depressive symptom are three times more likely to report lumbopelvic pain compared to those without [25].

The West Haven Multidimensional Pain Inventory (MPI) [26] is commonly used in studies concerned with chronic pain and was designed to capture the multidimensionality of chronic pain. Three clinically relevant subgroups are derived from the MPI instrument [27]; Interpersonally Distressed (ID), Dysfunctional (DYS), and Adaptive Copers (AC). Individuals in the ID subgroup is characterised by inadequate social support, and individuals in the DYS subgroup is characterised by high disability, affective distress, and pain intensity, while the AC group demonstrates a more successful adjustment to chronic pain.

There is a paucity of evidence in regard to psychosocial factors and its long-term association with pregnancy-related lumbopelvic pain. Therefore, the overall aim of this study was to investigate women with persistent pregnancy-related lumbopelvic pain 12 years postpartum based on psychosocial and behavioural characteristics using the MPI-S classification system. More specifically, we wanted to determine if women classified as ID or DYS, were more likely to report pain 12 years postpartum compared to women in the AC subgroup.
Secondly, we wanted to investigate if women assigned to the ID and DYS subgroup were more likely to report widespread pain, higher pain intensity, more days with pain, sick leave and disability pension compared to women in the AC subgroup. In addition, we also wanted to explore the use of prescription/non-prescription drugs and treatment sought among women with pregnancy-related lumbopelvic pain based on psychosocial and behavioural characteristics using the MPI-S. To the best of our knowledge the MPI has not been used for this condition previously.

\section{Methods \\ Study design}

This study is a cross-sectional study based on a previous cohort consisting of newly delivered women reporting lumbopelvic pain during their pregnancy in 2002. All women who had delivered from 1 January 2002 to 30 April 2002 at Departments of Obstetrics and Gynaecology at Umeå University Hospital (UUH), and Sunderby Hospital $(\mathrm{SH})$, in northern Sweden were invited to fill out the first questionnaire (Q1).

\section{Data collection}

Collection of data took place through four questionnaires; distributed right after delivery (Q1), 6 months after delivery (Q2), 14 months postpartum (Q3), and 12 years postpartum (Q4). To enable comparisons over time, similar questions were posed throughout the questionnaires. Additionally, instruments that have been shown to work well with patients with chronic musculoskeletal pain such as the EQ-5D [28, 29], Roland Morris Disability Questionnaire (RMDQ) [30], and the Swedish version of the Multidimensional Pain Inventory (MPI-S) [31], were included in Q4. Data collection of Q4 took place between May and June 2014. More detailed information regarding the data collection has been presented in previous publications $[6,32]$.

\section{Study participants}

The fourth questionnaires (Q4) were sent out to 624 women from the initial cohort $(n=639)$. A total of $n=$ 295 women responded to the questionnaire giving response rate of $47.3 \%$ (Fig. 1).

\section{Dependent variables}

The primary outcome measure was self-reported persistent pregnancy-related lumbopelvic pain 12 years postpartum using the previous definition in questionnaire Q1-Q3, where persistent pregnancy-related lumbopelvic pain was defined as 'continuous' or 'recurrent' pain in the lumbopelvic area over the past 12 months. The response alternative were 'yes, continuous pain,' 'yes, recurrent pain,' 'yes, pain on a few occasions', and 'no pain'. Women reporting 'continuous' or 'recurrent' pain the 


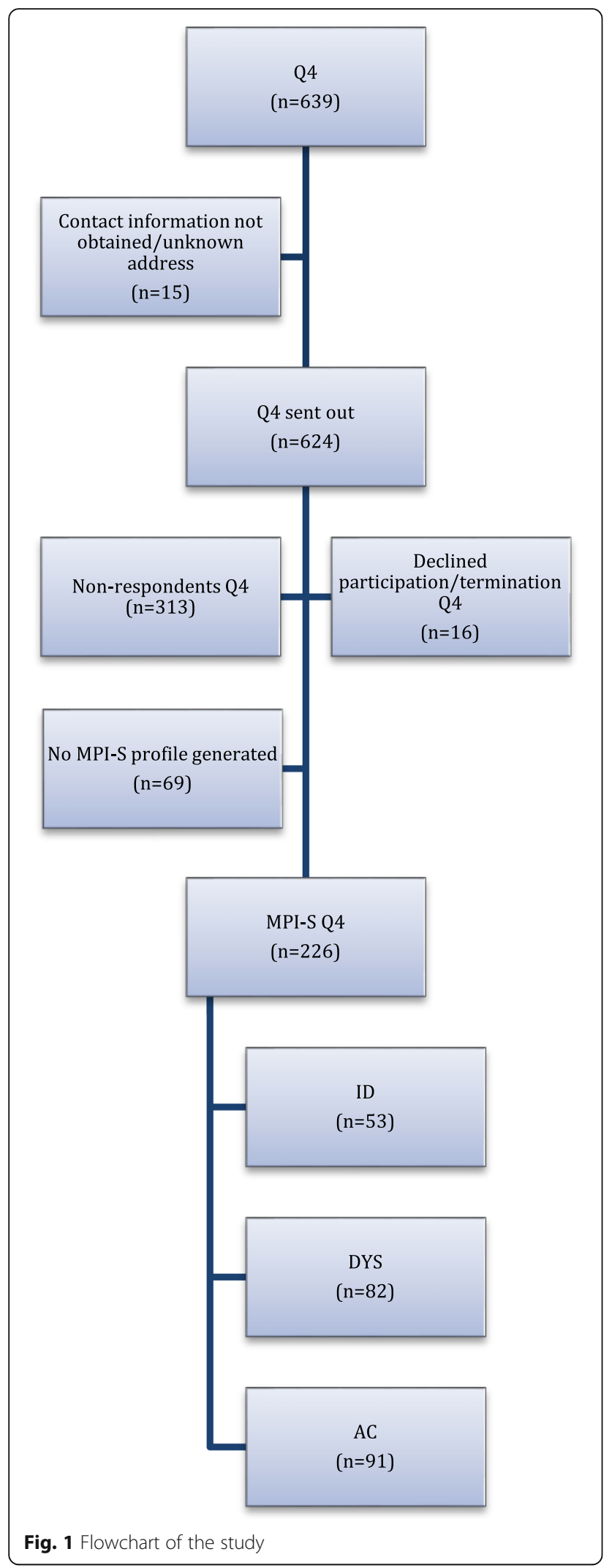

past 12 months were also asked to mark the area of pain on a schematic pain drawing [32]. The outcome variable was dichotomized into 'pain' and 'no pain' where women reporting pain on a few occasions were considered not to be in pain at Q4.

As secondary outcomes, neck pain (NP) and/or thoracic spinal pain (TSP) were dichotomized the same way as pain in the lumbopelvic area. Sciatica was defined as pain in one or both legs in relation to lumbopelvic pain the past 12 months. Pain intensity the past week and the past 12 months was reported through a visual analogue scale (VAS) of $100 \mathrm{~mm}(\mathrm{~mm})$, where 0 indicated 'no pain' and 100 'worst imaginable pain'. Pain intensity was dichotomized into scores above and below $70 \mathrm{~mm}$ on the VAS where women scoring $\geq 70 \mathrm{~mm}$ were considered to be in severe pain $[33,34]$. This cut-off score has previously been used for the same study group [4, 32, 35]. The participants were asked to estimate how many days the past 12 months they have had lumbopelvic pain with the response alternatives 'less than 30 days' and 'more than 30 days'. The same classification was done for days with NP/TSP the past 12 months. Participants were asked if they had been on sick leave due to lumbopelvic pain the past 12 months (response alternative 'yes' or 'no') and if so, how many days with the options '1-7 days in total', ' $8-14$ in total', and 'more than 15 days in total' (dichotomized to $<$ or $\geq 15$ days the past 12 months), and to what degree they had been on sick leave ('full-time' and 'part-time' including to what degree in percentage). To investigate granted disability pension, the question 'have you been granted disability pension due to lumbopelvic pain' was used with response alternatives 'yes' and 'no'.

To explore the use of prescription/non-prescription drugs the question 'do you take any prescription and/or non-prescription drugs on a regular basis' was used with the response alternatives 'yes' or 'no'. The participants were also asked to write the names of the prescription/ non-prescription drug/drugs they took on a regular basis. Furthermore, participants were asked if they had sought any healthcare/treatment due to lumbopelvic pain after their last pregnancy with the response alternatives 'yes' or 'no'.

\section{Independent variables}

Data regarding the participants' psychological and behavioural profile were collected at Q4 through the MPI-S instrument. The MPI is a psychometric tool developed to categorize chronic pain patients into more homogenous subgroups of patients [26, 27]. The MPI has been used in a variety of chronic pain condition such as NP and LBP [27, 36-39], headaches [40], temperomandibular disorders [41], fibromyalgia [42], and cancer pain [43]. The MPI classification strategy has been 
shown to be independent of age, pain duration, pathology, and has been replicated in several studies [44].

The Swedish version of the MPI (MPI-S) has shown acceptable reliability and validity across gender [45]. The MPI-S is comprised of 34 items, 8-scale inventory divided into one psychosocial and one behavioural section. The psychosocial section consists of five scales: pain severity (PS), pain-related interference of everyday life (I), perceived life control (LC), affective distress (AD), and perceived support from significant other (S). The behavioural part entails three scales measuring individual's perception of responses of significant others to display of pain and suffering. The three scales are: punishing responses (PR), solicitous responses (SR), and distracting responses (DR). All scales include a 7 numerical interval between 0 and 6 , where high scores indicate more of the characteristic in question.

Three different groups have empirically been derived from the MPI scales through cluster analysis and have been labelled: interpersonally distressed (ID), dysfunctional (DYS), and adaptive copers (AC) [27]. Individuals in the ID subgroup are characterised by inadequate social support, low solicitous response from significant other, and lower distracting response while individual in the DYS subgroup is characterised by high disability, affective distress, and pain intensity. Furthermore, individuals in the DYS subgroup are found to be more depressed, have more catastrophizing thoughts, low physical functioning, poor sleep quality and poor lifting capacity. The AC subgroup consists of individuals reporting a more successful adjustment to chronic pain compared both to ID and DYS individuals. AC individuals generally report low pain severity, low emotional distress, less catastrophizing thoughts, and better quality of sleep and physical functioning. The AC subgroup is considered to have the most favourable prognosis and less reported sick leave than both ID and DYS [37].

As not all responders had dated their questionnaire, mean age was calculated by subtracting the date of birth from January 1, 2015. Physical activity was investigated by asking the participants if they had exercised/done sports on a regular basis since their last pregnancy, with the response alternatives 'yes' or 'no'. Body Mass Index (BMI) at Q4 was calculated by kilograms $(\mathrm{kg}) /$ height $^{2}$ (meters). Self-rated health status (SRH) was investigated by asking the study participant to assess their current overall health status with the options: 'very good,' 'quite good, 'fair,' 'quite poor', and 'poor'. The options for relationship satisfaction were: 'very good,' 'good,' 'neither good or bad,' 'bad', and 'very bad'.

\section{Statistical methods}

The method used to derive the three different MPI-S subgroups was a non-hierarchical cluster procedure
(K-Means algorithm). Computations started with a standardisation of the MPI-S scales using the mean value and standard deviation to form Z-scores and then T-scores. The MPI-S subgroups were formed from the eight original scales using centroid vectors from a previously validated sample [31].

Descriptive statistics were used for all background variables of the three different MPI-S groups through the calculation of means and standard deviation (SD) for parametric data using one-way ANOVA. To test for differences between the MPI-S subgroups the independent t-test and Pearson's chi-square test was used as appropriate.

The dichotomized primary outcome of persistent pregnancy-related lumbopelvic pain 12 years postpartum was analysed using a robust modified Poisson regression [46] to determine the relative risk (RR) of reporting pain 12 years postpartum. The MPI-S subgroups were used as the predictive variable in the model. The same procedure was used for the secondary outcomes: pain intensity, days with pain, and sick leave as well as for the use of prescription/non-prescription drugs and treatment sought the past 12 months. The final model of the robust modified Poisson adjusted for LBP prior to pregnancy in 2002 improved the Akaike's Information Criterion (AIC) and the Bayesian Information Criterion (BIC). Due to violation of the normality assumption, pain intensity the past week as well as the past 12 months were also analysed by Kruskal-Wallis 1-way ANOVA on ranks; a suitable alternative for comparisons of three groups or more [47]. Additionally, the Mann-Whitney $U$ test was used to compare difference between two independent variables. As individuals belonging to the AC subgroup are considered better copers, the AC subgroup was used as the predefined reference group in all statistical analyses. All data was analysed using the SPSS v 24.0 software package. Statistical significance was set at $p<0.05$ when comparing differences among the three MPI-S subgroups.

\section{Ethics, consent and permission}

This study was approved by the Ethics Committee at the Umeå University (Dnr 2014-4-32 M supplement to Dnr 2012-404-31 M) and was performed in accordance with the Declaration of Helsinki. Written informed consent was obtained from all participants. No collection of details, images, or videos related to an individual person took place in this study.

\section{Results}

The Swedish version of the MPI (MPI-S)

The MPI-S classification procedure was carried on a total of $n=226$ women. Table 1 describes the MPI-S study population at Q4, where 53 women were classified as interpersonally distressed (ID), 82 as dysfunctional 
Table 1 Descriptive information on MPI-S subgroups

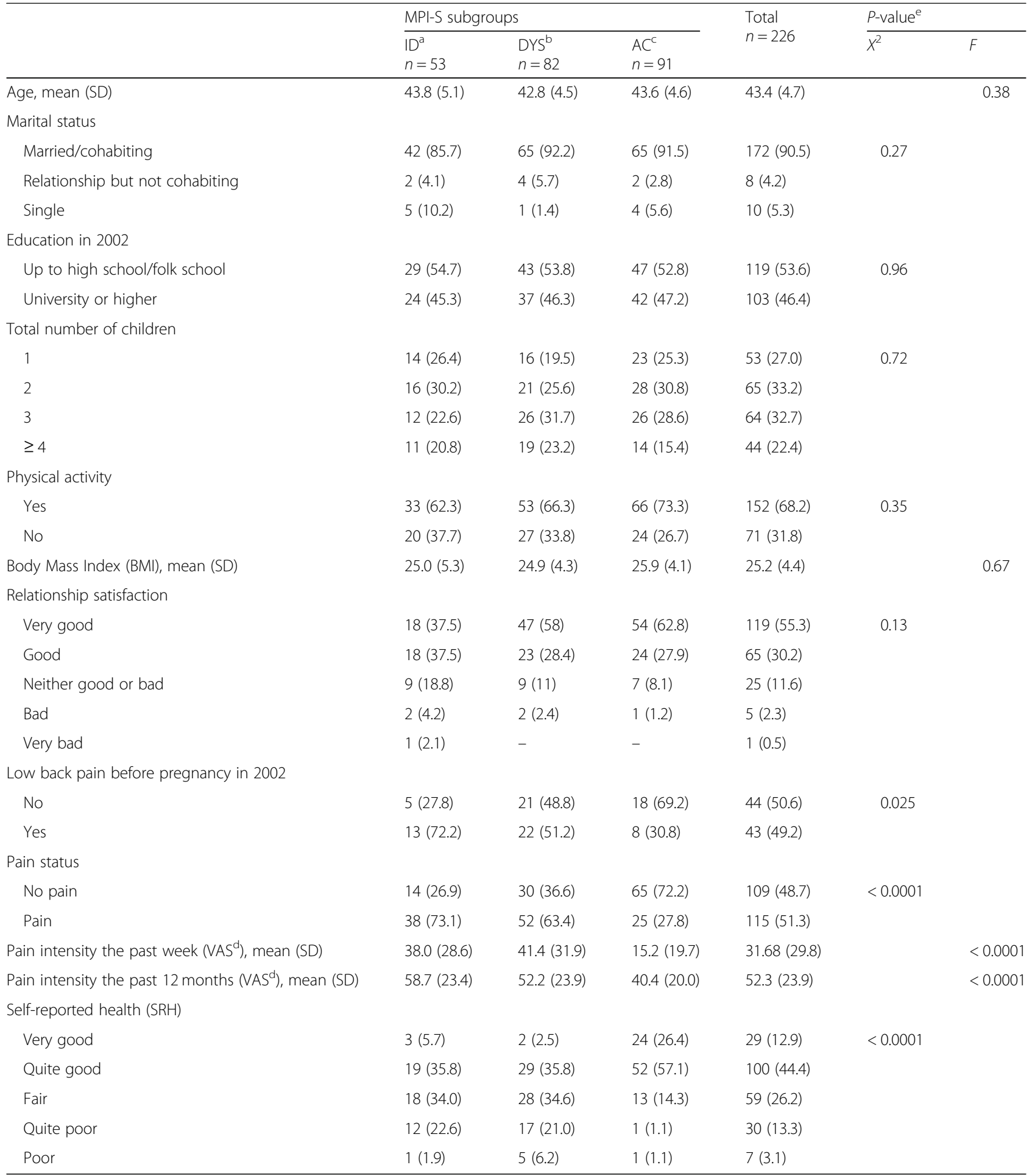

Numbers in parenthesis are percentage unless otherwise specified

anterpersonally distressed

${ }^{b}$ Dysfunctional

'Adapative copers

${ }^{d}$ Visual Analogue Scale

${ }^{\text {e}}$ Significance test $p<0.05$ 
(DYS), and 91 as adaptive copers (AC). The mean age across the MPI-S group was 43.4 years (SD 4.7). The vast majority of women were either married or cohabiting and $53.6 \%$ had a high school/folk school education. Most women reported having a total of 2 or 3 children and almost $70 \%$ of the women reported to participate in physical activity on a regular basis. Mean BMI across the study population was 25.2 (SD 4.4) $\mathrm{kg} / \mathrm{m}^{2}$ and most women reported to be satisfied with their relationship. No statistically significant difference was found between the MPI-S subgroups regarding the above-mentioned variables in Table 1 . Women in both the ID and DYS subgroup reported LBP before pregnancy in 2002 to a statistically significantly higher degree compared to the AC subgroup $(p=0.025)$. Additionally, a statistically significant difference were found between women in the ID and DYS subgroups compared to the AC subgroup in regard to pain status (pain versus no pain) at Q4 ( $p<$ $0.0001)$, pain intensity the past week $(p<0.0001)$ and the past 12 months $(p<0.0001)$, and SRH $(p<0.0001)$, where women in the $\mathrm{AC}$ subgroup reported pain at Q4 to a lesser degree, lower pain intensity both the past week (Fig. 2a) as well as the past 12 months (Fig. 2b). Women in the AC subgroup also reported better SRH at Q4 compared both to both the ID and DYS subgroups.

Table 2 gives an overview of descriptive data for the three individual subgroups (ID, DYS and AC). As expected, the descriptive data could differentiate between the individual subgroups and statistically significant differences were observed in all variables with the exception of NP/TSP the past 12 months, degree of sick leave and days of sick leave the past 12 months.

\section{Primary and secondary outcomes}

Women belonging to the ID and DYS subgroup had a RR of reporting pain 12 years postpartum (95\% confidence interval (CI) in parenthesis) of 2.57 (CI 1.763.75 ), $p<0.0001$ and 2.23 (CI 1.53-3.25), $p<0.0001$ respectively, compared to the AC subgroup (adjusting for LBP before pregnancy in 2002). Moreover, additional analyses demonstrated that women in the ID subgroup had a statistically significant increased RR in all variables with the exception of NP/TSP, sick leave and treatment sought the past 12 months compared to the AC subgroup. The DYS subgroups had a statistically significant increased RR in all variables, except NP/TSP, compared to the AC subgroup. Notable is that the DYS subgroup had more than 5 times increased RR of reporting sick leave the past 12 months compared to the AC subgroup at Q4 (RR 5.44; CI 1.70$17.38, p=0.004$ ) (Table 3). In addition, both the ID and DYS subgroup had an 8 to 11 times increased RR in reporting pain intensity of $\geq 70 \mathrm{~mm}$ both the past week and the past 12 months. Women in the ID and DYS subgroups also used antidepressants $\left(X^{2}(2, N=226)=6.92, p=0.031\right)$, paracetamol $\left(\mathrm{X}^{2}(2, N=226)=17.99, p>0.0001\right)$, opiates $\left(\chi^{2}(2, N=226)=7.04, p=0.03\right)$, and other drugs $\left(\chi^{2}(2, N=\right.$ $226)=8.70, p=0.031)$ to a statistically significant higher extent compared to the AC subgroup with the exception of Non-Steroid Anti-Inflammatory Drugs (NSAID) $\left(\mathrm{X}^{2}(2, N=226)=2.70, p=0.26\right)$ (Fig. 3).

Table 4 show that there was a statistically significant effect on the overall pain intensity the past week as well as pain intensity the past 12 months between the MPI-S subgroups $(p<0.0001)$. A statistically significant difference was also demonstrated regarding pain intensity the past week and the past 12 months between ID and AC and between DYS and AC, where women in the ID and DYS subgroup reported higher pain intensity in both variables compared to the AC subgroup (Table 4).

\section{Discussion}

This study aimed to investigate psychosocial and behavioural characteristics in women with persistent pregnancy-related lumbopelvic pain 12 years postpartum using the MPI-S. In this study we have demonstrated that it is possible to classify this group of women into clinically relevant subgroups using the MPI-S questionnaire. As hypothesized, women with more pronounced psychosocial difficulties (ID or DYS) were more than twice as likely to report pain 12 years postpartum compared to women belonging to the AC subgroup. Women in the ID and DYS subgroups also reported widespread pain to a higher extent, higher pain intensity, and more sick leave and disability pension compared to women in the AC subgroup. They also reported that they used prescription/non-prescriptions drugs to a higher degree and sought more treatment compared to women in the AC subgroup.

Together with previous episodes of LBP, psychological risk factors have been suggested to be of particular importance in the course of LBP $[15,16,48-50]$. Congruent with the findings in this study, emotional distress during pregnancy has been shown to be positively associated with severe persistent pregnancy-related lumbopelvic pain [51] and postpartum depressive symptoms has been demonstrated to be three times more prevalent in women with lumbopelvic pain compared to those not afflicted [25]. More extensive rehabilitation programs including counselling with focus on coping strategies may be more beneficial for patients with more pronounced psychosocial factors. A multidisciplinary approach is probably the most appropriate and effective intervention for patients with a variety of chronic musculoskeletal problem as it may help patients to lessens pain and disability, reduce number of sick days, and help the individual to faster return to work compared to physical treatment or usual care [52]. Consequently, it appears necessary to timeously address psychosocial factors in women with persistent pregnancy-related lumbopelvic 


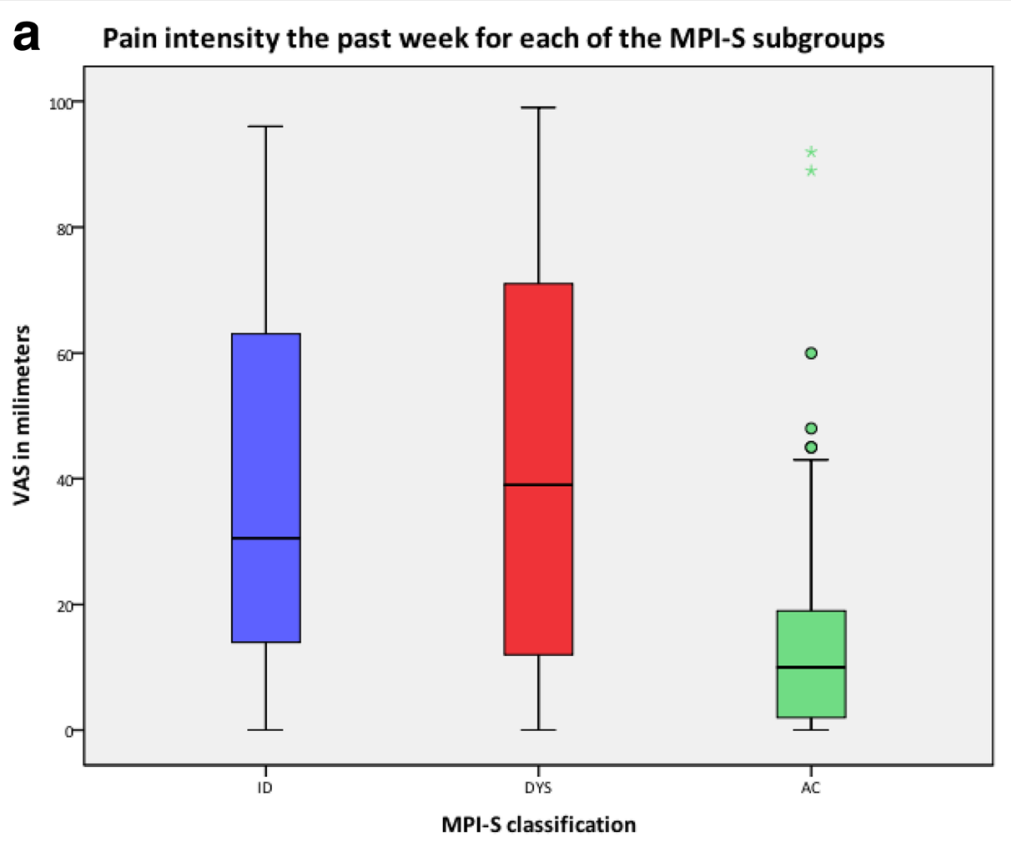

b

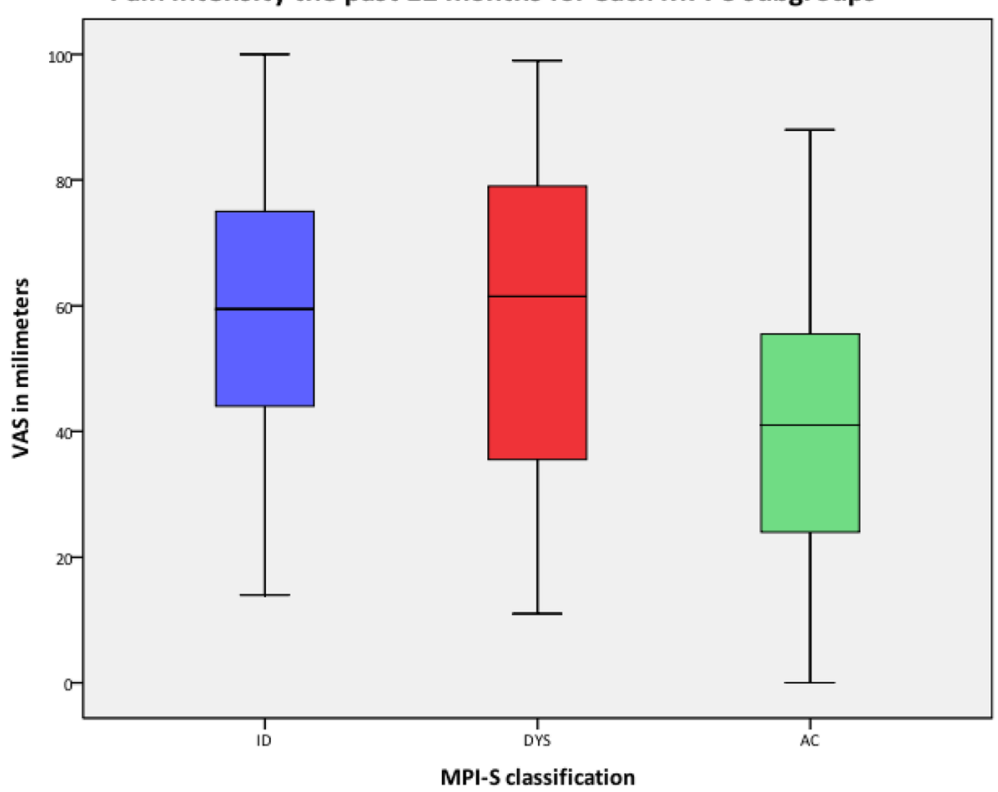

Fig. 2 a Pain intensity the past week for each of the MPI-S subgroups. b Pain intensity the past 12 months for each of the MPI-S subgroups

pain in an attempt to prevent symptoms to become chronic in nature.

Poor health-related qualities of life, kinesiophobia, high degree of disability and pain intensity, have been demonstrated to be linked to pregnancy-related lumbopelvic pain [53]. Persistent symptoms seem to negatively affect the ability to perform daily activities and women with persistent symptoms postpartum are often concerned about the possible progression of symptom [54]. As expected, women classified as ID and DYS demonstrated statistically increased risk in almost all secondary outcome variables compared to the AC subgroup. It is noteworthy that there were more than 5 times increased risk of women in the DYS subgroup to report sick leave the past 12 months compared to the AC subgroup (Table 3). These findings are similar to results in previous studies using the MPI questionnaire on populations with chronic LBP [37, 38]. Another study found that individuals with high levels of fear-avoidance were twice as likely to believe that sick leave is a good 
Table 2 Test for difference between MPI-S groups 12 years postpartum using Pearson's chi-square test

\begin{tabular}{cccc}
\hline $\mathrm{ID}^{\mathrm{a}}$ & $\mathrm{DYS}^{\mathrm{b}}$ & $\mathrm{AC}^{\mathrm{C}}$ & p-value \\
$n=53$ & $n=82$ & $n=91$ & \\
\hline
\end{tabular}

Pain intensity the past week $\left(\right.$ VAS $\left.^{d}\right)$

$\begin{array}{lllll}<70 \mathrm{~mm} & 43(81.1) & 62(75.6) & 89(97.8) & <0.0001 \\ \geq 70 \mathrm{~mm} & 10(18.9) & 20(24.4) & 2(2.2) & \end{array}$

Pain intensity the past 12 months $\left(V^{2} S^{d}\right)$

$\begin{array}{lllll}<70 \mathrm{~mm} & 37(69.8) & 55(67.1) & 88(96.7) & <0.0001 \\ \geq 70 \mathrm{~mm} & 16(30.2) & 27(32.9) & 3(3.3) & \end{array}$

Days with persistent LBP/PGP the past 12 months

$\begin{array}{lllll}<30 \text { days } & 11(23.9) & 24(31.6) & 45(71.4) & <0.0001 \\ \geq 30 \text { days } & 35(76.1) & 52(68.4) & 18(28.6) & \\ \text { Sciatica } & & & & \\ \text { No } & 13(28.3) & 22(29.3) & 37(58.7) & <0.0001 \\ \text { Yes } & 33(71.7) & 53(70.7) & 26(41.3) & \end{array}$

Neck or thoracic pain the past 12 months

$\begin{array}{lllll}\text { No } & 16(51.6) & 26(59.1) & 21(77.8) & 0.11 \\ \text { Yes } & 15(48.4) & 18(40.9) & 6(22.2) & \end{array}$

Days with neck or thoracic pain the past 12 months

$\begin{array}{llll}<30 \text { days } & 11(26.2) & 21(32.3) & 25(53.2) \\ \geq 30 \text { days } & 31(73.8) & 44(67.7) & 22(46.8)\end{array}$

Sick leave the past 12 months

$\begin{array}{lllll}\text { No } & 41(91.1) & 56(75.7) & 58(95.1) & 0.003 \\ \text { Yes } & 4(8.9) & 18(24.3) & 3(4.9) & \\ \text { Degree of sick leave } & & & \\ \text { Full-time } & 6(100) & 15(88.2) & 2(66.7) & 0.34 \\ \text { Part-time } & - & 2(11.8) & 1(33.3) & \end{array}$

Days of sick leave the past 12 months

$\begin{array}{lllll}<15 \text { days } & 2(50.0) & 8(44.4) & 2(50.0) & 0.97 \\ \geq 15 \text { days } & 2(50.0) & 10(55.6) & 2(50.0) & \\ \text { Granted disability pension } & & & \\ \text { No } & 39(88.6) & 68(90.7) & 57(100) & 0.042 \\ \text { Yes } & 5(11.4) & 7(9.3) & - & \end{array}$

Prescription and/or non-prescription drugs

$\begin{array}{lllll}\text { No } & 22(41.5) & 33(40.7) & 58(65.2) & 0.002 \\ \text { Yes } & 31(58.5) & 48(59.3) & 31(34.8) & \end{array}$

Treatment sought since last delivery due to persistent LBP/PGP

$\begin{array}{lllll}\text { No } & 26(56.5) & 26(34.2) & 43(70.5) & <0.0001 \\ \text { Yes } & 20(43.5) & 50(65.8) & 18(29.5) & \end{array}$

Numbers in parenthesis are percentage unless otherwise specified

anterpersonally distressed

${ }^{b}$ Dysfunctional

'Adapative copers

dVisual Analogue Scale

esignificance test $p<0.05$ treatment for LBP compared to individuals with low levels of fear-avoidance [55]. The individual beliefs about LBP, comorbidities, and coping abilities appear to be the most important reasons for sick leave due to LBP [56]. This could possibly explain why women belonging to the AC subgroup reported statistically significant less sick leave compared to the DYS subgroup, as the AC subgroup is characterized by less pain intensity and co-morbidities, better coping abilities, and have a more positive outlook on LBP.

Patients on analgesics medications incur higher cost to society [10] and the World Health Organisation (WHO) has ranked depression as the single largest contributor to global disability [57]. In this study, prescription/non-prescription drugs were used to a significant lesser extent in the AC subgroup compared to both the ID and DYS subgroup. Women in the ID subgroup reported use of antidepressants drugs to a statistically significant higher extent compared to women in the DYS and AC subgroup. Even though individuals belonging to the DYS subgroup have been found to be significantly more depressed compared to individuals in the ID subgroup [44], there may be different factors contributing to symptoms of depression in the two subgroups. Depressive symptoms in ID individuals may be more contributed to marital and interpersonally difficulties, lack of support from significant other compared to individuals in the DYS subgroup [31, 44]. ID individuals rated the quality of their interpersonal relationship as lower compared to both DYS and AC subgroups [44] and this was also true in this study, though not to a statistically significant degree. Worrisome is the high use of opiates among women in the DYS subgroup, especially considering the unknown long-term effectiveness and safety of opioids [58] as well as the emerging evidence that long-term opioid use increases the risk of abnormal menstruation and of menopausal symptoms in women [59].

\section{Methodological considerations}

This study has some limitations that need to be discussed. Failure to respond to parts of the MPI questionnaire renders an unclassifiable profile [60,61]. A total of 69 women did not respond to sufficient numbers of questions of the MPI-S questionnaire and had to be excluded due to missing data in the two different section of the MPI-S. This negatively impacted the number of women in each of the MPI-S subgroups, hence, reducing statistical power and increased the risk of Type II error in the analysis of the data. The MPI-S was only distributed at Q4 and may infer that the women in this study could have changed MPI-S groups over the course of the study. Even though classification changes can occur over time (mostly in the AC subgroup) several studies have confirmed the MPI classification system internal 
Table 3 Risk ratios for the MPI-S groups using $A C^{c}$ as reference of the explantory variable, estimated by modified Poisson regression and adjusted for low back pain prior to pregnancy in 2002

\begin{tabular}{|c|c|c|c|c|c|c|c|c|}
\hline & $I D^{a}$ & & & & DYS $^{b}$ & & & \\
\hline & $\mathrm{n}(\%)$ & $\mathrm{RR}$ & $\mathrm{Cl}(95 \%)$ & $p$-value & $\overline{n(\%)}$ & $\mathrm{RR}$ & $\mathrm{Cl}(95 \%)$ & $p$-value $e^{e}$ \\
\hline Pain status 12 years post partum & $49(22.5)$ & & & & $79(36.2)$ & & & \\
\hline No pain & & 1 & & & & 1 & & \\
\hline Pain & & 2.57 & $1.76-3.75$ & $<0.0001$ & & 2.23 & $1.53-3.25$ & $<0.0001$ \\
\hline Days with lumbopelvic pain the past 12 months & $43(24.2)$ & & & & $73(41.0)$ & & & \\
\hline$<30$ days & & 1 & & & & 1 & & \\
\hline$\geq 30$ days & & 2.63 & $1.72-4.03$ & $<0.0001$ & & 2.35 & $1.55-3.57$ & $<0.0001$ \\
\hline Pain intensity the past week $\left(\right.$ VAS $\left.^{d}\right)$ & $50(22.8)$ & & & & $79(36.1)$ & & & \\
\hline$<70 \mathrm{~mm}$ & & 1 & & & & 1 & & \\
\hline$\geq 70 \mathrm{~mm}$ & & 8.38 & $1.90-37.00$ & 0.005 & & 11.00 & $2.66-45.48$ & 0.001 \\
\hline Pain intensity the past 12 months $\left(\right.$ VAS $^{d}$ ) & $50(22.8)$ & & & & $79(36.1)$ & & & \\
\hline$<70 \mathrm{~mm}$ & & 1 & & & & 1 & & \\
\hline$\geq 70 \mathrm{~mm}$ & & 9.43 & $2.89-30.72$ & $<0.0001$ & & 9.32 & $2.94-29.57$ & $<0.0001$ \\
\hline Sciatica & $43(24.3)$ & & & & $72(40.7)$ & & & \\
\hline No & & 1 & & & & 1 & & \\
\hline Yes & & 1.81 & $1.27-2.58$ & 0.001 & & 1.77 & $1.26-2.48$ & 0.001 \\
\hline Neck and/or thoracic pain & $28(29.5)$ & & & & $41(43.2)$ & & & \\
\hline No & & 1 & & & & 1 & & \\
\hline Yes & & 2.09 & $0.94-4.62$ & 0.07 & & 1.98 & $0.92-4.26$ & 0.08 \\
\hline Days with neck or thoracic pain the past 12 months & $39(26.5)$ & & & & $62(42.2)$ & & & \\
\hline$<30$ days & & 1 & & & & 1 & & \\
\hline$\geq 30$ days & & 1.62 & $1.12-2.34$ & 0.01 & & 1.51 & $1.05-2.16$ & 0.03 \\
\hline Sick leave the past 12 months & $42(24.3)$ & & & & $71(41.0)$ & & & \\
\hline No & & 1 & & & & 1 & & \\
\hline Yes & & 2.13 & $0.51-8.82$ & 0.30 & & 5.44 & $1.70-17.38$ & 0.004 \\
\hline Treatment sought the past 12 months & $43(24.4)$ & & & & $73(41.5)$ & & & \\
\hline No & & 1 & & & & 1 & & \\
\hline Yes & & 1.51 & $0.91-2.52$ & 0.11 & & 2.28 & $1.50-3.46$ & $<0.0001$ \\
\hline Prescription and/or non-prescription drugs & $50(23.1)$ & & & & $78(36.1)$ & & & \\
\hline No & & 1 & & & & 1 & & \\
\hline Yes & & 1.66 & $1.13-2.43$ & 0.009 & & 1.70 & $1.20-2.41$ & 0.003 \\
\hline
\end{tabular}

Numbers in parenthesis are percentage unless otherwise specified

Interpersonally distressed

${ }^{b}$ Dysfunctional

${ }^{c}$ Adapative copers

dVisual Analogue Scale

eSignificance test $p<0.05$

reliability, validity and generalizability both in interventional and observational studies in patients with chronic musculoskeletal pain [31, 62-64]. In addition, the Swedish version of the MPI (MPI-S) has shown good reliability and validity across gender [45] and no difference in pain duration or medical variables [31].

Conversely to studies where we investigated individuals with chronic musculoskeletal pain using the MPI-S [38, 65], the number of individuals in the AC subgroup is high. This seems reasonable, as approximately $60 \%$ of women responding to the Q4 reported no pain 12 years postpartum [6]. Moreover, studies investigating NP and LBP in a gainfully employed population have demonstrated that the AC subgroup is commonly larger than both the ID and the DYS subgroup [36, 37].

This cross-sectional study is part of a cohort of women that commenced in 2002. At that point, today's 


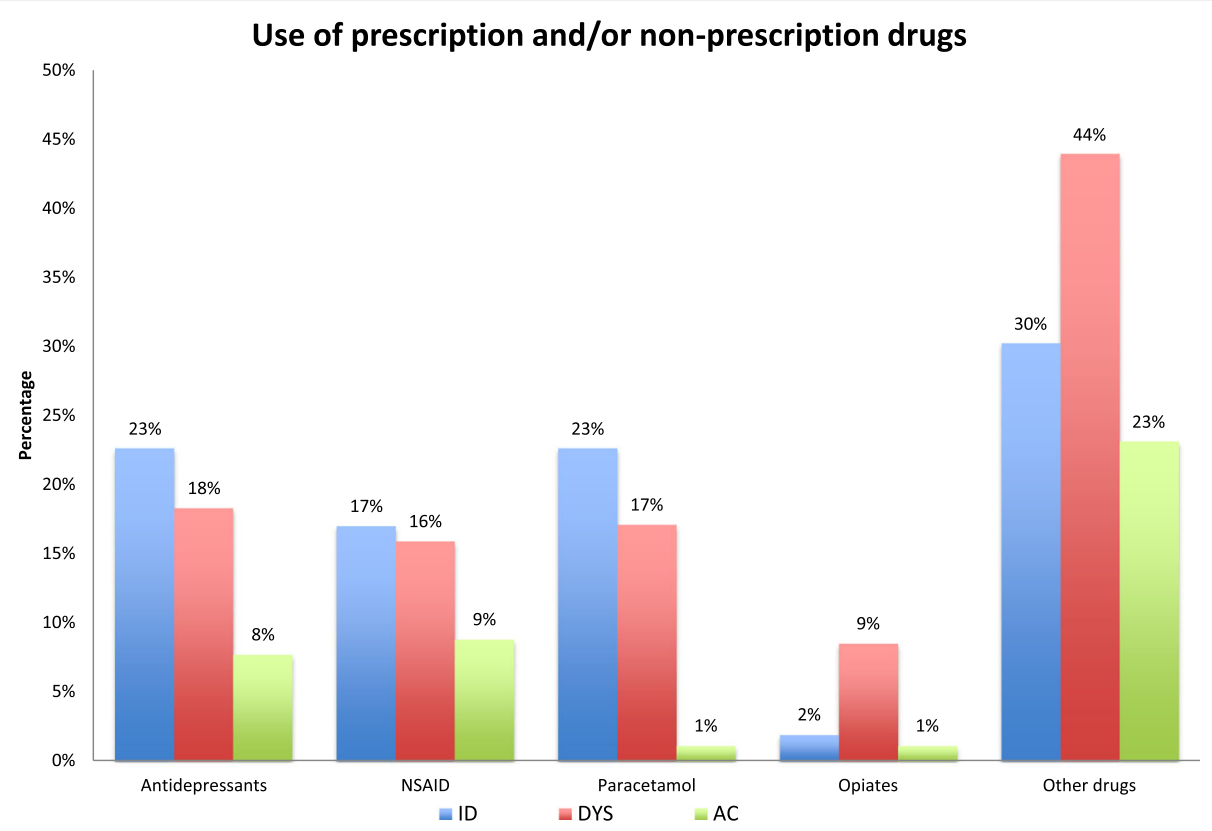

Fig. 3 Use of prescription and/or non-prescription drugs for each of the MPI-S subgroups

definition of PGP based on positive diagnostic tests as well as pain upon palpation of the ligaments and joints of the pelvis was not available. Instead pain drawings were used in this study to describe pain location $[6,32]$. However, it is impossible to exclude pain from the lumbar area or a combination of PGP and LBP, as it strongly correlates to the same anatomical location as non-specific LBP. Yet, it has been demonstrated that there is an increased risk of persistent pregnancy-related lumbopelvic pain if a woman is diagnosed with both LBP and PGP during pregnancy [66]. Swedish women under the age of 65 are overrepresented in the statistics regarding chronic LBP [67] and the estimated prevalence of LBP in women in the age group 40-49 years is $35 \%$ [68]. LBP is commonly regarded as stable over time, while pelvic pain increases during pregnancy [69]; hence factors and outcomes in this study are probably mostly related to pregnancy-related pelvic pain.

Baseline data (Q1) was complete on all subjects and analysis of the data collected through Q4 showed that non-responders did not differ significantly in the majority of variables compared to responders [6].
Convenience sampling of doublet questionnaires (Q4) were able to show that most questions showed adequate to excellent agreement [6] and questions in Q4 were very similar to those in Q1-Q3. Data collected after delivery (Q2-Q3) has been regarded to be representative of Swedish women with persistent PGP [32]. About 19\% of women responding to Q4 reported pain to various degree 12 years postpartum, which is in line with other long-term follow-up studies of women with persistent pregnancy-related lumbopelvic pain $[3,8]$.

\section{Conclusions}

This study is unique as it is the first study attempting to classify women with persistent pregnancy-related lumbopelvic pain into psychosocial derived subgroups. We were able to demonstrate that a multidimensional approach to classification of women with persistent pregnancy-related lumbopelvic pain based on psychosocial and behavioural characteristics, can further distinguish different clinically relevant subgroups in women with persistent symptoms 12 years postpartum. The

Table 4 Comparing highest level of pain at Q4 using the AC group as the reference group

\begin{tabular}{|c|c|c|c|c|c|c|c|c|c|}
\hline \multirow{2}{*}{$\begin{array}{l}\text { Highest level } \\
\text { of pain }\end{array}$} & \multicolumn{4}{|l|}{ ID } & \multicolumn{4}{|c|}{ DYS } & \multirow{2}{*}{$\begin{array}{l}p \text {-value } \\
\text { KW-test }\end{array}$} \\
\hline & $\bar{n}$ & Median $^{a}$ & $\mathbb{R}^{\mathrm{b}}$ & $p$-value MW-test & $\bar{n}$ & Median $^{a}$ & $\mathbb{R}^{\mathrm{b}}$ & $p$-value MW-test & \\
\hline Past week & 46 & 30.5 & 51 & $<0.0001$ & 75 & 39 & 59 & $<0.0001$ & $<0.0001$ \\
\hline Past 12 months & 46 & 59.5 & 34 & $<0.0001$ & 76 & 61.5 & 44 & $<0.0001$ & $<0.0001$ \\
\hline
\end{tabular}

${ }^{\mathrm{a}}$ Median Mann-Whitney $\mathrm{U}$ test. ${ }^{\mathrm{b}} I R$ Interquartile Range. ${ }^{\mathrm{C}}$ Kruskal-Wallis $p$-value

Significant result $p<0.05$ using Mann-Whitney $U$ test

Significant result $p<0.05$ using Kruskal-Wallis test 
MPI-S classification system together with clinical data, early and customized interventions with a multidisciplinary approach could thus improve clinical outcomes for women with persistent pregnancy-related lumbopelvic pain and reduce the economic burden on the social security and healthcare systems. Future research concerning women with pregnancy-related lumbopelvic pain needs to take psychosocial and behavioural characteristics into consideration.

\section{Abbreviations \\ AC: Adaptive copers; BMI: Body mass index; Cl: Confidence interval; DYS: Dysfunctional; ID: Interpersonally distressed; LBP: Low back pain; MPI- S: Multidimensional Pain Inventory - Swedish version; NP: Neck pain; NSAID: Non-Steroid Anti-Inflammatory Drugs; PPGP: Persistent pelvic girdle pain; RMDQ: Roland Morris Disability Questionnaire; RR: relative risk; TSP: Thoracic spinal pain; VAS: Visual analogue scale}

\section{Acknowledgements}

The authors wish to acknowledge all women in this study that shared their obstetric history and experiences with us. We also thank Sophia Holmlund for her assistance in the data collection.

\section{Funding}

This study was funded through grants from the European Chiropractors' Union Research Council, Stiftelsen Sigurd och Elsa Goljes Minne, the County Council of Västerbotten, and Umeå University.

\section{Availability of data and materials}

The datasets used and/or analysed during the current study are available from the corresponding author on reasonable request.

\section{Authors' contributions}

All authors have read and approved the final manuscript. CB was involved in the study design, data collection, analysis and interpretation of the data, drafting and revising of the manuscript and has given final approval. MP was involved in the study design, data collection, interpretation of data, and revision of the manuscript and gave final approval. IM was involved in study design, interpretation of data, and revision of the manuscript, and gave final approval.

\section{Ethics approval and consent to participate}

This study was approved by the Ethics Committee at the Umeå University (Dnr 2014-4-32 M supplement to Dnr 2012-404-31 M) and was performed in accordance with the Declaration of Helsinki. Written informed consent was obtained from all participants. No collection of details, images, or videos related to an individual person took place in this study.

\section{Consent for publication}

Not applicable in this study.

\section{Competing interests}

The authors declare that they have no competing interests.

\section{Publisher's Note}

Springer Nature remains neutral with regard to jurisdictional claims in published maps and institutional affiliations.

\section{Author details}

'Department of Clinical Sciences, Obstetrics and Gynecology, Umeå University, 90187 Umeå, Sweden. ²Department of Nursing, Umeå University, 90187 Umeå, Sweden.

Received: 28 December 2018 Accepted: 10 May 2019 Published online: 13 August 2019

\section{References}

1. Gutke A, Ostgaard HC, Oberg B. Predicting persistent pregnancy-related low back pain. Spine. 2008;33(12):E386-93.
2. Ostgaard HC, Roos-Hansson E, Zetherstrom G. Regression of back and posterior pelvic pain after pregnancy. Spine. 1996;21(23):2777-80.

3. Albert $H$, Godskesen $M$, Westergaard J. Prognosis in four syndromes of pregnancy-related pelvic pain. Acta Obstet Gynecol Scand. 2001;80(6): 505-10.

4. Bergstrom C, Persson M, Mogren I. Pregnancy-related low back pain and pelvic girdle pain approximately 14 months after pregnancy - pain status, self-rated health and family situation. BMC Pregnancy Childbirth. 2014;14:48.

5. Bergstrom C, Persson M, Mogren I. Sick leave and healthcare utilisation in women reporting pregnancy related low back pain and/or pelvic girdle pain at 14 months postpartum. Chiropr Man Therap. 2016;24:7.

6. Bergstrom C, Persson M, Nergard KA, Mogren I. Prevalence and predictors of persistent pelvic girdle pain 12 years postpartum. BMC Musculoskelet Disord. 2017;18(1):399.

7. Elden H, Gutke A, Kjellby-Wendt G, Fagevik-Olsen M, Ostgaard HC. Predictors and consequences of long-term pregnancy-related pelvic girdle pain: a longitudinal follow-up study. BMC Musculoskelet Disord. 2016;17(1):276

8. Noren L, Ostgaard S, Johansson G, Ostgaard HC. Lumbar back and posterior pelvic pain during pregnancy: a 3-year follow-up. Eur Spine J. 2002;11(3):267-71.

9. Kent P, Keating JL. Classification in nonspecific low back pain: what methods do primary care clinicians currently use? Spine. 2005:30(12):1433-40.

10. Gustavsson A, Bjorkman J, Ljungcrantz C, Rhodin A, Rivano-Fischer M, Sjolund KF, et al. Socio-economic burden of patients with a diagnosis related to chronic pain--register data of 840,000 Swedish patients. Eur J Pain. 2012;16(2):289-99.

11. Gatchel RJ, Turk DC. Psychosocial factors in pain : critical perspectives, vol. xvii. New York: Guilford Press; 1999. p. 510.

12. Burton AK, Tillotson KM, Main CJ, Hollis S. Psychosocial predictors of outcome in acute and subchronic low back trouble. Spine. 1995;20(6):722-8.

13. Hoogendoorn WE, van Poppel MN, Bongers PM, Koes BW, Bouter LM. Systematic review of psychosocial factors at work and private life as risk factors for back pain. Spine. 2000;25(16):2114-25.

14. Macfarlane GJ, Thomas E, Croft PR, Papageorgiou AC, Jayson MI, Silman AJ. Predictors of early improvement in low back pain amongst consulters to general practice: the influence of pre-morbid and episode-related factors. Pain. 1999;80(1-2):113-9.

15. Linton SJ. A review of psychological risk factors in back and neck pain. Spine. 2000;25(9):1148-56.

16. Pincus T, Burton AK, Vogel S, Field AP. A systematic review of psychological factors as predictors of chronicity/disability in prospective cohorts of low back pain. Spine. 2002;27(5):E109-20,

17. Hill JC, Dunn KM, Lewis M, Mullis R, Main CJ, Foster NE, et al. A primary care back pain screening tool: identifying patient subgroups for initial treatment. Arthritis Rheum. 2008:59(5):632-41.

18. Kamper SJ, Maher CG, Hancock MJ, Koes BW, Croft PR, Hay E. Treatmentbased subgroups of low back pain: a guide to appraisal of research studies and a summary of current evidence. Best Pract Res. 2010;24(2):181-91.

19. Carmody T. Psychosocial subgroups, coping, and chronic low-back pain. J Clin Psychol Med Settings. 2001;8(3):137-48.

20. Grotle M, Foster NE, Dunn KM, Croft P. Are prognostic indicators for poor outcome different for acute and chronic low back pain consulters in primary care? Pain. 2010;151(3):790-7.

21. Hill JC, Whitehurst DG, Lewis M, Bryan S, Dunn KM, Foster NE, et al. Comparison of stratified primary care management for low Back pain with current best practice (STarT Back): a randomised controlled trial. Lancet. 2011;378(9802):1560-71.

22. Robinson PS, Balasundaram AP, Vollestad NK, Robinson HS. The association between pregnancy, pelvic girdle pain and health-related quality of life - a comparison of two instruments. J Patient Rep Outcomes. 2018;2:45.

23. Mackenzie J, Murray E, Lusher J. Women's experiences of pregnancy related pelvic girdle pain: a systematic review. Midwifery. 2018;56:102-11.

24. Albert HB, Godskesen M, Korsholm L, Westergaard JG. Risk factors in developing pregnancy-related pelvic girdle pain. Acta Obstet Gynecol Scand. 2006;85(5):539-44.

25. Gutke A, Josefsson A, Oberg B. Pelvic girdle pain and lumbar pain in relation to postpartum depressive symptoms. Spine. 2007;32(13):1430-6.

26. Kerns RD, Turk DC, Rudy TE. The west haven-Yale multidimensional pain inventory (WHYMPI). Pain. 1985;23(4):345-56.

27. Turk DC, Rudy TE. Toward an empirically derived taxonomy of chronic pain patients: integration of psychological assessment data. J Consult Clin Psychol. 1988;56(2):233-8. 
28. Bjork S, Norinder A. The weighting exercise for the Swedish version of the EuroQol. Health Econ. 1999;8(2):117-26.

29. Quercioli C, Messina G, Barbini E, Carriero G, Fani M, Nante N. Importance of sociodemographic and morbidity aspects in measuring health-related quality of life: performances of three tools: comparison of three questionnaire scores. Eur J Health Econ. 2009;10(4):389-97.

30. Johansson E, Lindberg P. Subacute and chronic low back pain. Reliability and validity of a Swedish version of the Roland and Morris disability questionnaire. Scand J Rehabil Med. 1998;30(3):139-43.

31. Bergstrom G, Bodin L, Jensen IB, Linton SJ, Nygren AL. Long-term, nonspecific spinal pain: reliable and valid subgroups of patients. Behav Res Ther. 2001:39(1):75-87.

32. Mogren IM, Pohjanen Al. Low back pain and pelvic pain during pregnancy: prevalence and risk factors. Spine. 2005;30(8):983-91.

33. Collins SL, Moore RA, McQuay HJ. The visual analogue pain intensity scale: what is moderate pain in millimetres? Pain. 1997;72(1-2):95-7.

34. Jensen MP, Chen C, Brugger AM. Interpretation of visual analog scale ratings and change scores: a reanalysis of two clinical trials of postoperative pain. J Pain. 2003;4(7):407-14.

35. Mogren I. Perceived health, sick leave, psychosocial situation, and sexual life in women with low-back pain and pelvic pain during pregnancy. Acta Obstet Gynecol Scand. 2006;85(6):647-56.

36. Eklund A, Bergstrom G, Bodin L, Axen I. Do psychological and behavioral factors classified by the west haven-Yale multidimensional pain inventory (Swedish version) predict the early clinical course of low back pain in patients receiving chiropractic care? BMC Musculoskelet Disord. 2016;17:75.

37. Bergstrom C, Hagberg J, Bodin L, Jensen I, Bergstrom G. Using a psychosocial subgroup assignment to predict sickness absence in a working population with neck and back pain. BMC Musculoskelet Disord. 2011:12:81.

38. Bergstrom G, Bergstrom C, Hagberg J, Bodin L, Jensen I. A 7-year follow-up of multidisciplinary rehabilitation among chronic neck and back pain patients. Is sick leave outcome dependent on psychologically derived patient groups? Eur J Pain. 2010;14(4):426-33.

39. Turk DC, Rudy TE. The robustness of an empirically derived taxonomy of chronic pain patients. Pain. 1990;43(1):27-35.

40. Walter $L$, Brannon $L$. A cluster analysis of the multidimensional pain inventory. Headache. 1991;31 (7):476-9.

41. Turk DC. Strategies for classifying chronic orofacial pain patients. Anesth Prog. 1990;37(2-3):155-60.

42. Turk DC, Okifuji A, Sinclair JD, Starz TW. Pain, disability, and physical functioning in subgroups of patients with fibromyalgia. J Rheumatol. 1996; 23(7):1255-62.

43. Turk DC, Fernandez E. On the putative uniqueness of cancer pain: do psychological principles apply? Behav Res Ther. 1990;28(1):1-13.

44. Turk DC. The potential of treatment matching for subgroups of patients with chronic pain: lumping versus splitting. Clin J Pain. 2005;21(1):44-55 discussion 69-72

45. Bergstrom KG, Jensen IB, Linton SJ, Nygren AL. A psychometric evaluation of the Swedish version of the multidimensional pain inventory (MPI-S): a gender differentiated evaluation. Eur J Pain. 1999;3(3):261-73.

46. Zou G. A modified poisson regression approach to prospective studies with binary data. Am J Epidemiol. 2004;159(7):702-6.

47. Chan Y, Walmsley RP. Learning and understanding the Kruskal-Wallis oneway analysis-of-variance-by-ranks test for differences among three or more independent groups. Phys Ther. 1997;77(12):1755-62.

48. George $\mathrm{C}$. The six-month incidence of clinically significant low back pain in the Saskatchewan adult population. Spine. 2002;27(16):1778-82.

49. Hestbaek L, Leboeuf-Yde C, Manniche C. Low back pain: what is the longterm course? A review of studies of general patient populations. Eur Spine J. 2003;12(2):149-65.

50. Jones GT, Johnson RE, Wiles NJ, Chaddock C, Potter RG, Roberts C, et al. Predicting persistent disabling low back pain in general practice: a prospective cohort study. Br J Gen Pract. 2006;56(526):334-41.

51. Bjelland EK, Stuge B, Engdahl B, Eberhard-Gran M. The effect of emotional distress on persistent pelvic girdle pain after delivery: a longitudinal population study. BJOG. 2013;120(1):32-40,

52. Nanadiego F, Seffinger M. Multidisciplinary biopsychosocial rehabilitation improves outcomes for patients with chronic low Back pain. J Am Osteopath Assoc. 2016;116(5):327-8.
53. Gutke A, Lundberg M, Ostgaard HC, Oberg B. Impact of postpartum lumbopelvic pain on disability, pain intensity, health-related quality of life, activity level, kinesiophobia, and depressive symptoms. Eur Spine J. 2011;20(3):440-8.

54. Wuytack F, Curtis E, Begley C. Experiences of first-time mothers with persistent pelvic girdle pain after childbirth: descriptive qualitative study. Phys Ther. 2015;95(10):1354-64

55. Linton SJ, Vlaeyen J, Ostelo R. The back pain beliefs of health care providers: are we fear-avoidant? J Occup Rehabil. 2002;12(4):223-32.

56. Werner EL, Cote P. Low back pain and determinants of sickness absence. Eur J Gen Pract. 2009;15(2):74-9.

57. World Health Organization. Depression and Other Common Mental Disorders. Geneva: Global Health Estimates; 2017. https://www.who.int/ mental_health/management/depression/prevalence_global_health_ estimates/en/. Accessed 16 May 2019.

58. Deyo RA, Von Korff M, Duhrkoop D. Opioids for low back pain. BMJ. 2015; 350:g6380.

59. Richardson E, Bedson J, Chen Y, Lacey R, Dunn KM. Increased risk of reproductive dysfunction in women prescribed long-term opioids for musculoskeletal pain: a matched cohort study in the clinical practice research datalink. Eur J Pain. 2018;22(9):1701-8.

60. Broderick JE, Junghaenel DU, Turk DC. Stability of patient adaptation classifications on the multidimensional pain inventory. Pain. 2004;109(1-2):94-102.

61. Okifuji A, Turk DC, Eveleigh DJ. Improving the rate of classification of patients with the multidimensional pain inventory (MPI): clarifying the meaning of "significant other". Clin J Pain. 1999;15(4):290-6.

62. Junghaenel DU, Broderick JE. Validation of the MPI patient profiles by partners and healthcare providers. Pain. 2009;144(1-2):130-8.

63. Verra ML, Angst F, Staal JB, Brioschi R, Lehmann S, Aeschlimann A, et al. Reliability of the multidimensional pain inventory and stability of the MPI classification system in chronic back pain. BMC Musculoskelet Disord. 2012;13:155.

64. Bergstrom G, Jensen IB, Bodin L, Linton SJ, Nygren AL, Carlsson SG. Reliability and factor structure of the multidimensional pain inventory-Swedish language version (MPI-S). Pain. 1998;75(1):101-10.

65. Bergstrom C, Jensen I, Hagberg J, Busch H, Bergstrom G. Effectiveness of different interventions using a psychosocial subgroup assignment in chronic neck and back pain patients: a 10-year follow-up. Disabil Rehabil. 2012;34(2):110-8.

66. Gausel AM, Kjaermann I, Malmqvist S, Dalen I, Larsen JP, Okland I. Pelvic girdle pain 3-6 months after delivery in an unselected cohort of Norwegian women. Eur Spine J. 2016;25(6):1953-9.

67. Ahlberg I. Kostnader för rörelseorganens sjukdomar i Sverige år 2012. 2012. https://ihe.se/publicering/kostnader-rorelseorganens-sjukdomar-sverige-ar2012/. Accessed 16 May 2019.

68. Hoy D, Bain C, Williams G, March L, Brooks P, Blyth F, et al. A systematic review of the global prevalence of low back pain. Arthritis Rheum. 2012; 64(6):2028-37.

69. Ostgaard HC, Andersson GB, Karlsson K. Prevalence of back pain in pregnancy. Spine. 1991;16(5):549-52.

Ready to submit your research? Choose BMC and benefit from:

- fast, convenient online submission

- thorough peer review by experienced researchers in your field

- rapid publication on acceptance

- support for research data, including large and complex data types

- gold Open Access which fosters wider collaboration and increased citations

- maximum visibility for your research: over $100 \mathrm{M}$ website views per year

At $\mathrm{BMC}$, research is always in progress.

Learn more biomedcentral.com/submissions 